\title{
Effective Joining of Pre-cast Concrete Slabs with Self-compacting HSFRCC
}

\author{
Angus K.F. Cheung ${ }^{1}$ and Christopher K.Y. Leung ${ }^{2}$
}

Received 26 June 2010, accepted 19 January 2011

\begin{abstract}
In the pre-cast construction of concrete structures, the minimization of the joint size and simplification of its design can greatly improve construction efficiency. This paper reports the result of an experimental study on the use of high strength fiber reinforced cementitious composites (HSFRCC) for the joining of precast concrete slabs. In order for the joined slab to have similar bending behavior as a monolithic slab, sufficient bond length between the HSFRCC and reinforcing bars is required to ensure steel yielding before bond failure. To control the material cost, the fiber content in the HSFRCC is limited to 2\%. To find a suitable bond length, direct Tension Pull-out Bond Test (DTP-BT) was first conducted on steel bars embedded in HSFRCC with compressive strength of $150 \mathrm{MPa}$. The testing parameters included the anchorage length ( $5 \mathrm{~d}$ or $8 \mathrm{~d}$, where $\mathrm{d}$ is the steel bar diameter, $16 \mathrm{~mm}$ ) and type of steel bar (straight, hooked and nut at the end). According to the test results, $8 \mathrm{~d}$ is sufficient for steel yielding to occur in a joint with $2 \%$ of micro-steel fiber. Monolithic slabs as well as slabs with HSFRCC joints were then prepared and tested in bending. Similar load displacement performance was observed for the two kinds of slabs, demonstrating the effectiveness of the HSFRCC joint.
\end{abstract}

\section{Introduction}

In the construction of pre-cast concrete structures, the design of joints between components is a critical issue. For the sake of construction efficiency, the reinforcement details within the joint should be as simple as possible, and the width of the joint should be small. The latter is particularly important for construction in cold regions, where the joint may have to be heated to facilitate the strength development of concrete. In this case, a short joint will significantly reduce the energy required.

The width of the joint is governed by the bond capacity between the reinforcing steel and concrete - the lap length between the reinforcements coming out from the end of adjacent pre-cast members must be sufficient for loading to be fully transmitted from one member to the other. Conventionally, the transfer length is designed to be sufficiently long for full yielding of steel reinforcements to occur. According to BS8110 (1997), for normal concrete, this length is over $15 \mathrm{~d}$ ( $\mathrm{d}$ is reinforcement diameter) or $300 \mathrm{~mm}$, whichever is greater. Moreover, in some cases, a significant amount of looped reinforcements or transverse steel bars is required to prevent bond failure within the joint area. As a result, both the cost and construction time are significantly increased.

To improve the bond capacity of lapped reinforcement,

\footnotetext{
${ }^{1}$ Postdoctoral researcher, Department of Civil Engineering, Hong Kong University of Science and Technology, Hong Kong.

E-mail: angusust@ust.hk

${ }^{2}$ Professor (Head), Department of Civil Engineering, Hong Kong University of Science and Technology, Hong Kong.
}

application of anchored reinforcement in high strength concrete was studied. According to Azizinamini et al. (1993, 1995), the assumption of uniform bond stress distribution over the anchorage length is valid for normal strength concrete (below $70 \mathrm{MPa}$ ) but not applicable to high strength concrete. Due to the more significant improvement of reinforcement bearing capacity than tensile strength of concrete when concrete compressive strength is increased, failure could be by splitting prior to achieving uniform bond stress distribution. The presence of transverse reinforcement is able to enhance the splitting resistance of concrete. Hamad and Machaka (1999) reported the increase of bond strength of reinforcement in silica fume concrete by the use of transverse reinforcement in the splice region. Besides transverse reinforcement, fiber reinforced concrete is able to provide higher splitting resistance. Harajli et al. (2002) showed the increase of bond strength by $26 \%$ and $33 \%$ in normal strength concrete by adding $1 \%$ and $2 \%$ in volume of fibers. According to Hamad et al. (2001), bond strength and ductility of high strength concrete beam specimens (up to $78 \mathrm{MPa}$ ) with spliced bars was improved by using steel fibers $(0.5 \%$ to $2 \%$ in volume). Researchers in Denmark (Jensen et al. 1995; Hansen and Heshe 2001) and Japan (Shioya et al. 1997) have investigated the use of high strength fiber reinforced cementitious materials (HSFRCC) as joining material for precast concrete beams/slabs. In Jensen et al. (1995), an anchorage test was performed with HSFRCC with $6 \%$ of steel fiber. The test results indicate that an anchorage length as short as $60 \mathrm{~mm}$ is sufficient to induce yielding of deformed high yield steel bars with $8 \mathrm{~mm}$ diameter. Similar results were found in Hansen and Heshe (2001), who observed rupture of $16 \mathrm{~mm}$ deformed steel bar in the anchorage test when the embedded length was 11 times the bar diameter 
(d). In the test specimens, transverse reinforcement of 12 mm diameter was incorporated. Shioya et al. (1997) employed HSFRCC to construct a joint between two precast panels. According to results from flexural tests, members containing $19 \mathrm{~mm}$ steel bars with lap length of $190 \mathrm{~mm}$ within the joint exhibit similar strength and ductility to monolithic beams. According to the above studies, the use of HSFRCC can significantly reduce the required bond length for steel yielding to occur. With the use of superplasticizer, HSFRCC with $150 \mathrm{MPa}$ strength and self-compacting behaviour can be produced (Ma and Dietz 2002). This will greatly facilitate the preparation of a short joint with HSFRCC as compaction is not required.

This paper presents a further investigation on the use of HSFRCC as joining materials. The objective of this investigation is to study the feasibility of a small and simple joint in a precast concrete slab that is able to behave similarly to a monolithic concrete slab in bending. Self-compacting HSFRCC with compressive strength of $150 \mathrm{MPa}$ is applied as the joining material. While existing studies indicate outstanding performance of HSFRCC as joining material with a high volume percentage (up to $6 \%$ ) of micro-steel fiber, only $2 \%$ of micro-steel fiber is adopted in this study, as such amount of fiber is sufficient to provide tensile strain-hardening behavior. Due to the high cost of micro-steel fiber, a significant reduction in fiber content will enhance the feasibility for practical applications. To make the joint design as simple as possible, no transverse reinforcement is applied.

In designing the joint, the major concern is the bond behavior between the steel reinforcement and HSFRCC. The direct tension pull-out bond test (DTP-BT) is therefore performed first to identify a suitable bond length that is (i) sufficiently short, and (ii) enough for steel yielding to occur before bond failure. In this study, we focus on the joining of slabs. Steel reinforcing bar with $16 \mathrm{~mm}$ diameter is used because re-bars larger than this size are seldom employed for slabs. The DTP-BT test is performed with two steel embedded lengths, $5 \mathrm{~d}$ and $8 \mathrm{~d}$, which are below that in most bond tests reported in the literature. While we do not attempt to perform a large number of tests to find the shortest embedded length for yielding to occur, we hope to provide new test results that show an improvement over existing ones (e.g., steel yielding achieved with shorter embedded length or comparable embedded length at lower fiber content). In addition to straight rebars (SB), testing is also carried out with hooked end re-bar (HB) or re-bar with a nut at its end (NB), to study the effect of end bearing on bond capacity.

According to BS8110 (1997), the concrete cover for common structures is usually $20 \mathrm{~mm}$ to $50 \mathrm{~mm}$ depending on the exposure conditions. As both the bar diameter and concrete cover could affect the mode of failure (e.g. splitting or pull out of bar) as well as the pull-out load capacity, two concrete covers $(52 \mathrm{~mm}$ and $30 \mathrm{~mm})$ or cover-to-bar diameter (c/d ratios 3.25 and 1.875) are employed in our tests. The effect of the steel embedded length, concrete cover and bar type on the pull-out load capacity and failure mode are discussed. After determining the suitable bond length to ensure steel yielding, precast slabs with joints of the appropriate length are made together with a control monolithic slab (with no joint). These slabs are tested in bending to illustrate the effectiveness of the HSFRCC joint.

\section{Material compositions and properties}

HSFRCC are ultra high strength fiber reinforced cementitious composites consisting of a binder system comprised of Portland cement, pozzolanic additives, as well as silica sands and micro-steel fiber. The mix proportion of HSFRCC is shown in Table 1. To get high strength, a low W/B ratio 0.19 was employed. Also, silica fume was added to fill the small voids among cement particles so as to obtain a denser microstructure. $20 \%$ by weight of Portland cement was replaced by fly ash to enhance workability and reduce heat generation at the early age. Of course, silica fume and fly ash would also contribute to the formation of C-S-H through the pozzolanic reaction. According to Caliskan (2003), the presence of silica fume gives denser and less porous transition zones, resulting in higher compressive strength of the matrix. Chan and Chu (2004) showed the improvement of bond strength of short steel fiber in high strength concrete by silica fume. The optimal silica fume/concrete ratio was found to be $20-30 \%$ based on the bond strength of pull-out energy in their experimental results. However, according to Yang and Zhang (2004), the increase of silica fume content in the mix leads to higher autogenous

Table 1 Mix proportion of HSFRCC.

\begin{tabular}{|c|c|c|c|c|c|c|c|c|}
\hline \multirow{2}{*}{$\begin{array}{l}\text { Cement } \\
\left(\mathrm{kg} / \mathrm{m}^{3}\right)\end{array}$} & \multirow{2}{*}{$\begin{array}{l}\text { Fly ash } \\
\left(\mathrm{kg} / \mathrm{m}^{3}\right)\end{array}$} & \multirow{2}{*}{$\begin{array}{l}\text { Silica fume } \\
\left(\mathrm{kg} / \mathrm{m}^{3}\right)\end{array}$} & \multicolumn{3}{|c|}{$\begin{array}{l}\text { Silica sand }{ }^{1)} \\
\quad\left(\mathrm{kg} / \mathrm{m}^{3}\right)\end{array}$} & \multirow{2}{*}{$\begin{array}{c}\text { Water } \\
\left(\mathrm{kg} / \mathrm{m}^{3}\right)\end{array}$} & \multirow{2}{*}{$\begin{array}{c}\mathrm{SP}^{2)} \\
\left(\mathrm{kg} / \mathrm{m}^{3}\right)\end{array}$} & \multirow{2}{*}{$\begin{array}{c}\text { Steel fiber } \\
(\%)\end{array}$} \\
\hline & & & Type 1 & Type 2 & Type 3 & & & \\
\hline 1010 & 247 & 112 & 141 & 316 & 417 & 260 & 11.5 & 2 \\
\hline
\end{tabular}

1) Silica sand: Type 1: 300 - 1180 $\mu \mathrm{m}$ Type 2: 150 - $600 \mu \mathrm{m} \quad$ Type 3: $53-300 \mu \mathrm{m}$

2) BASF Superplasticizer: a) ACE $80: 80 \%$ b) B211: $20 \%$

3) Elkem U920 silica fume 
shrinkage due to low internal humidity of the matrix. In this study, the weight fraction of silica fume was therefore limited to $5 \%$ of the total solid weight. Silica sands of three different sizes were employed, and their relative proportion was determined according to the guideline proposed by Fuller and Thompson (1926) to give a well packed system. The maximum size of silica sand was limited to $1.2 \mathrm{~mm}$ to ensure that the steel fibers are well distributed in the matrix. Micro-steel fibers with 0.16 $\mathrm{mm}$ diameter and $13 \mathrm{~mm}$ length were used. The bridging effect of the steel fibers improves the resistance to crack propagation under loading. With the use of polycarboxylate superplasticizers (from BASF), the HSFRCC mortar exhibited self-compactibility. In this study, the workability of HSFRCC with $2 \%$ fiber content was measured by both a slump flow test and U-channel flow test. In the slump flow test, the flow distance reached a value of $680 \mathrm{~mm}$ (Fig. 1a). In the U-channel flow test, negligible height difference was measured between the two sides of the container (Fig. 1b).

The basic material properties of HSFRCC were determined from compressive, tensile and flexural tests. All specimens were cured for 28 days before testing. The compression test was performed on $100 \mathrm{~mm}$ cube specimens. The average compressive strength of plain high strength concrete (HSC) with the composition listed in Table 1 but no fibers was found to be $150 \mathrm{MPa}$, while the strength of HSFRCC was $160 \mathrm{MPa}$. Tensile testing was performed on $350 \times 15 \times 50 \mathrm{~mm}$ specimens with the setup illustrated in Fig. 2. The stress-strain curves for three separate specimens are shown in Fig. 3(a). The HSFRCC shows a clear strain hardening regime before reaching an average tensile strength of over $9 \mathrm{MPa}$. On further deformation, softening behavior can be observed. The flexural behavior of HSFRCC was obtained from 4-point bending of $300 \times 75 \times 75 \mathrm{~mm}$ beam specimens. Figure 3(b) shows the flexural stress vs. mid-point displacement curve for two HSFRCC specimens and two HSC specimens. The presence of micro steel fiber of $2 \%$ volume fraction not only enhances the ductility of the material, but also improves the flexural strength by about $60 \%$.

In addition to HSFRCC specimens, two sets of specimens were also prepared with normal concrete of 70 $\mathrm{MPa}$ strength. The results can illustrate the different performance between high strength and normal strength concrete.

\section{DTP-BT}

\subsection{Specimens preparation}

To study the bonding behaviour of deformed bar in HSFRCC, the direct tension pull-out bond test (DTP-BT) was performed. The size of the block was $360 \times 120 \times$ $120(\mathrm{~mm})$ for specimens with $52 \mathrm{~mm}$ cover on all sides and $360 \times 120 \times 98(\mathrm{~mm})$ for those with $30 \mathrm{~mm}$ cover on one side. As shown in Fig. 4, the specimen consists of two deformed bars of diameter $16 \mathrm{~mm}$ that are aligned in

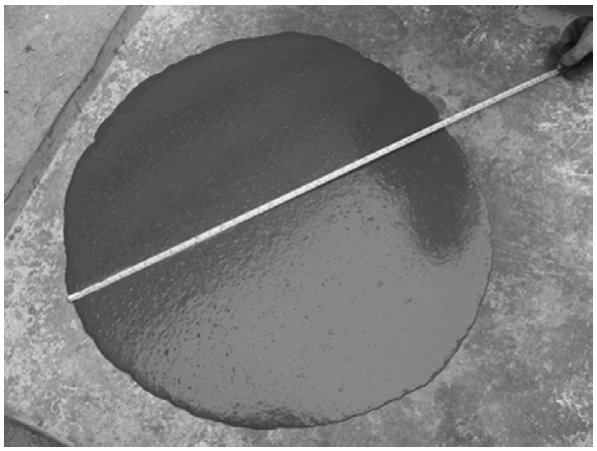

(a)

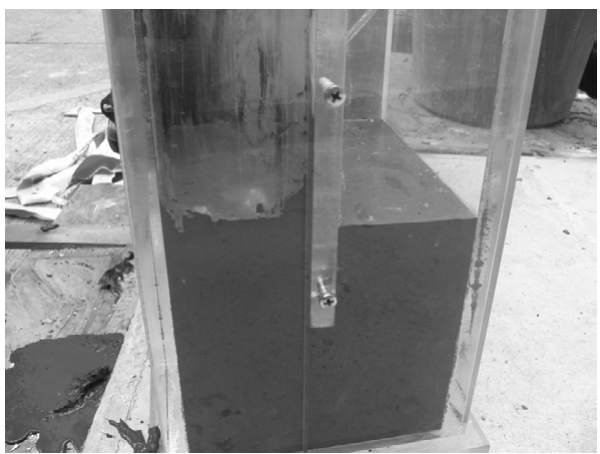

(b)

Fig. 1 (a) Slump flow test, (b) U-channel flow test of HSFRCC.

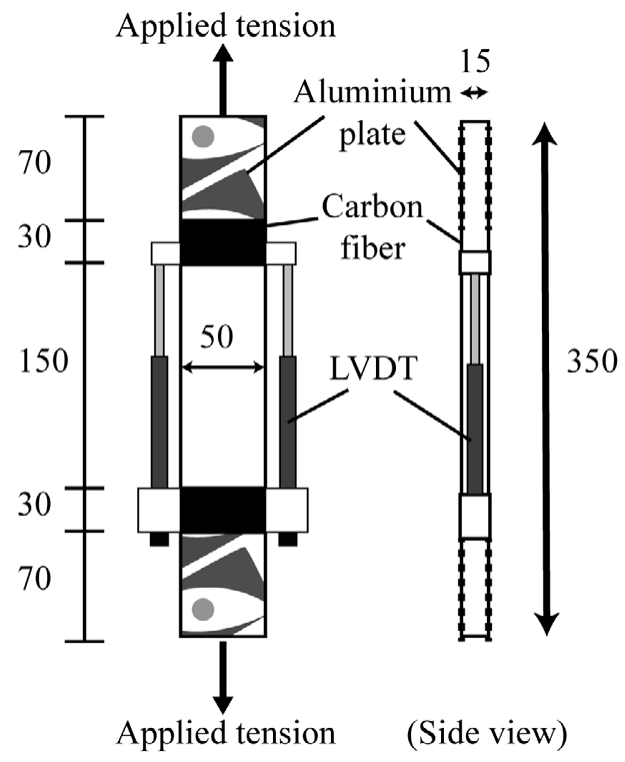

Fig. 2 Setup for direct tension test.

a concrete block. The steel bar with the shorter embedded length (or anchorage length) is referred to as the anchorage bar and the other bar with longer embedded length, which is not expected to govern the failure, is called the support bar. In the tests, the support bar was maintained at $150 \mathrm{~mm}$ embedded length, while the length of the anchorage test bar was varied. For all specimens, 


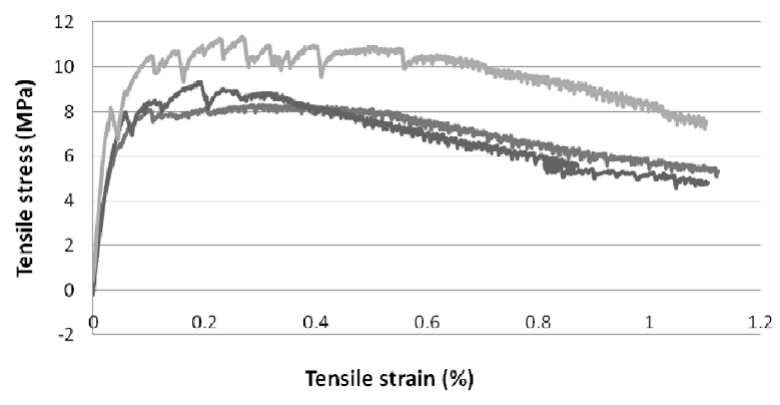

(a) Tensile stress vs. strain curves

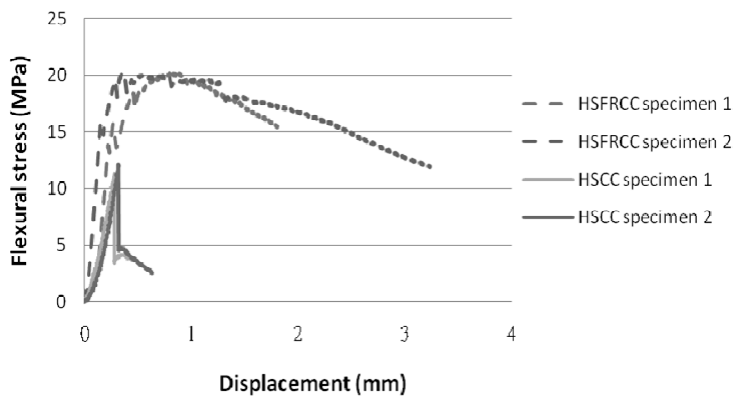

(b) Typical flexural stress vs. strain curve

Fig. 3 Tensile and flexural behavior of HSFRCC.

the anchorage and support bars were made with high yield steel bar of $500 \mathrm{MPa}$ yield strength and about 650 $\mathrm{MPa}$ rupture strength. As the primary purpose of this work is to develop HSFRCC for joining precast slab components, the bar diameter (d) was selected to be 16 $\mathrm{mm}$ as this is the maximum bar size for most common concrete slabs. To prevent tensile failure of the concrete specimen, longitudinal steel reinforcements $(12 \mathrm{~mm}$ deformed bar) were placed near the four edges of the specimen (see Fig. 4).

The DTP-BT specimens with various testing parameters are summarized in Table 2. Following Aarup et al. (2000), who performed similar tests on steel bars in high fiber volume HSFRCC with anchorage lengths of $6 \mathrm{~d}$ to 9 $\mathrm{d}(\mathrm{d}=16 \mathrm{~mm})$, the anchorage length in this study was set to $5 \mathrm{~d}$ and $8 \mathrm{~d}$. Testing was first performed with straight bars. To show the advantage of HSFRCC over conventional concrete, specimens were also prepared with

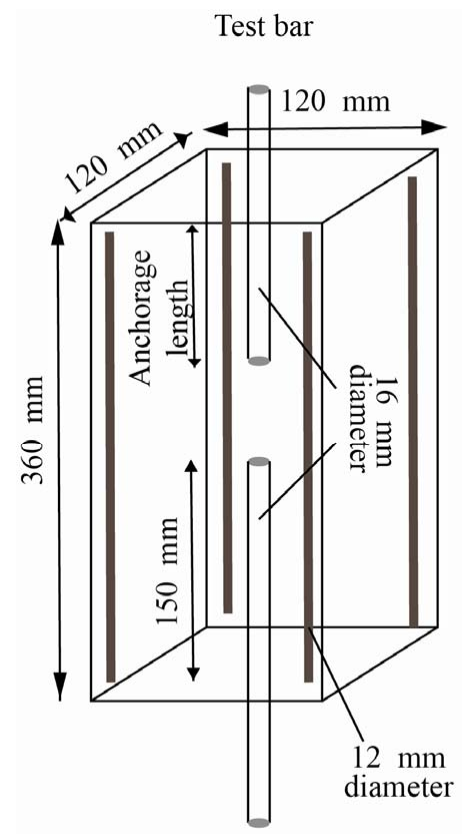

Support bar

Fig. 4 Direct tension pull-out bond test specimen. normal concrete of $70 \mathrm{MPa}$ compressive strength. In these specimens, transverse steel reinforcements were added as in conventional practice to confine the concrete. Specifically, four mild steel stirrups of $10 \mathrm{~mm}$ diameter were fixed on the longitudinal reinforcements near the edges (see Fig. 5a). The stirrups spacing was $80 \mathrm{~mm}$ as smaller spacing is uncommon in practice. For specimens using HSFRCC, no transverse reinforcement was added. To highlight the effect of fibers, specimens with no fiber and $2 \%$ fibers were tested.

To study the bearing effect of the bar on the bond capacity in HSFRCC, hooked-end bars and bars with a welded nut (Fig. 5) were also tested. According to BS8110 (1997), the concrete cover for common structures is usually 20 to $50 \mathrm{~mm}$ depending on the exposure

Table 2 DTP-BT specimens.

\begin{tabular}{|c|c|c|c|c|}
\hline \multicolumn{2}{|r|}{ Batches } & $\begin{array}{l}\text { Anchorage } \\
\text { length }\end{array}$ & $\begin{array}{l}\text { Bar } \\
\text { type }\end{array}$ & Fiber \\
\hline 1 & C -5d-SB-0\%* & $5 \mathrm{~d}$ & \multirow{6}{*}{$\begin{array}{c}\text { Straight } \\
\text { bar }\end{array}$} & \multirow{4}{*}{$0 \%$} \\
\hline 2 & C -8d-SB-0\%* & $8 \mathrm{~d}$ & & \\
\hline 3 & HC- 5d-SB-0\% & $5 \mathrm{~d}$ & & \\
\hline 4 & HC- $8 \mathrm{~d}-\mathrm{SB}-0 \%$ & $8 \mathrm{~d}$ & & \\
\hline 5 & HC- 5d-SB-2\% & $5 \mathrm{~d}$ & & \multirow{10}{*}{$2 \%$} \\
\hline 6 & HC- $8 d-S B-2 \%$ & $8 \mathrm{~d}$ & & \\
\hline 7 & HC-5d-HB-2\% & $5 d$ & \multirow{2}{*}{$\begin{array}{c}\text { Hook } \\
\text { bar }\end{array}$} & \\
\hline 8 & HC-8d-HB-2\% & $8 \mathrm{~d}$ & & \\
\hline 9 & HC-5d-NB-2\% & $5 d$ & \multirow{2}{*}{$\begin{array}{c}\text { Bar with } \\
\text { a nut }\end{array}$} & \\
\hline 10 & HC-8d-NB-2\% & $8 \mathrm{~d}$ & & \\
\hline 11 & $\begin{array}{c}\text { HC- } \\
5 \mathrm{~d}-\mathrm{SB} 30-2 \%\end{array}$ & $5 d$ & \multirow{2}{*}{$\begin{array}{c}\text { Straight } \\
\text { bar } \\
\text { (30 mm } \\
\text { cover) }\end{array}$} & \\
\hline 12 & $\begin{array}{c}\text { HC- } \\
\text { 8d-SB30-2\% }\end{array}$ & $8 \mathrm{~d}$ & & \\
\hline 13 & $\begin{array}{c}\text { HC- } \\
\text { 5d-HB30-2\% }\end{array}$ & $5 d$ & \multirow{2}{*}{$\begin{array}{c}\text { Hook } \\
\text { bar } \\
\text { (30 mm } \\
\text { cover) }\end{array}$} & \\
\hline 14 & $\begin{array}{c}\text { HC- } \\
\text { 8d-HB-30-2\% }\end{array}$ & $8 \mathrm{~d}$ & & \\
\hline
\end{tabular}

C: Concrete, HC: HSFRCC/HSC (high strength concrete without fiber)

* For normal concrete specimens, transverse steel reinforcements were added 
conditions. In our work, most tests were performed with a cover of $52 \mathrm{~mm}$ (c/d ratio 3.25) (which is suitable for outdoor exposure, such as bridge structures or balconies of buildings). In addition, members with $30 \mathrm{~mm}(\mathrm{c} / \mathrm{d}$ ratio 1.875 ) cover on one side (which can be employed for indoor members or outdoor members under 'harmless' environments) and $52 \mathrm{~mm}$ on the other side of the bar were also tested. As the test results of straight bars and bars with a nut were similar, only straight bars and hooked bars were tested for specimens with a cover of 30 $\mathrm{mm}$.

In Table 2, the specimens are denoted in a way to reflect the various testing parameters. The first group of letters in the notation represents the type of concrete, $\mathrm{C}$ for normal concrete (to provide comparison) and $\mathrm{HC}$ for high strength matrix. The second group ( $5 \mathrm{~d}$ or $8 \mathrm{~d}$ ) indicates the anchorage length. The third one indicates the use of straight bars (SB), hooked bars (HB), or bars with a welded nut (NB). For the specific cases with $30 \mathrm{~mm}$ cover, the letters ' 30 ' are included in this letter group. The last letter group ( $0 \%$ or $2 \%)$ indicates the presence or absence of steel fibers. As an example, HC-5d-SB30-2\% represents a specimen made with HSFRCC with $2 \%$ of steel fibers, containing a straight anchor bar, and having an anchorage length of $5 \mathrm{~d}$.

In the preparation of pull-out bond test specimens, test

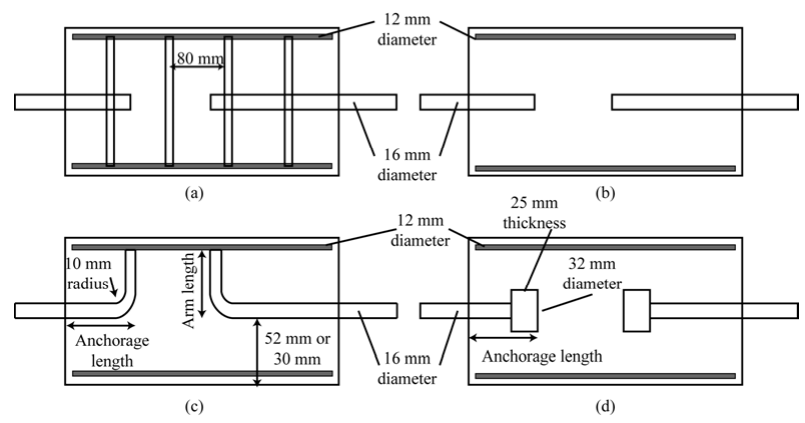

Fig. 5 Various kinds of bond test specimens. (a) with straight bar and transverse reinforcement, (b) with straight bar and no transverse reinforcement, (c) with hooked bar, (d) with bar having a nut at the end.

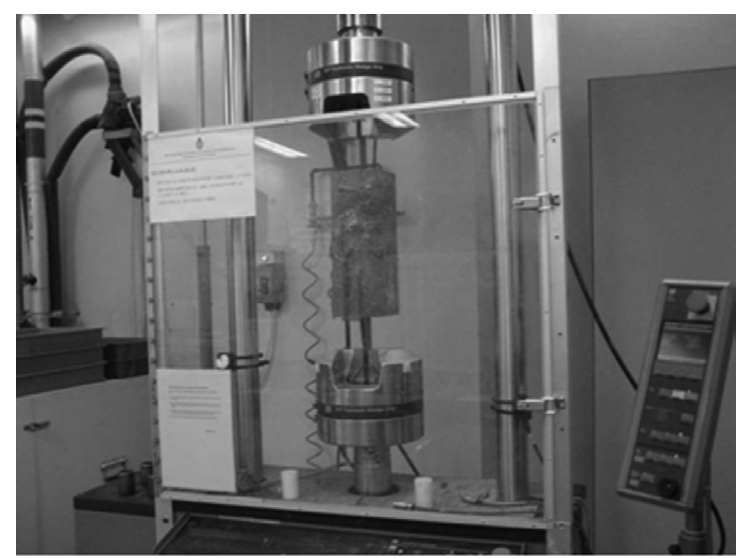

Fig. 6 Experimental setup of DTP-BT. bars with specified anchorage lengths and bar type were placed inside the steel moulds together with the bars near the edges and the steel stirrups (if necessary). Special care was taken to ensure proper alignment of the test bars and support bars, as any misalignment will induce bending that affects the accuracy of the results. Three specimens were prepared and tested for each batch. All specimens were cured under $98 \%$ relative humidity and $25^{\circ} \mathrm{C}$ temperature until the age of 28 days. Specimens were then removed from the curing room for testing.

\subsection{DTP-BT testing setup}

Figure 6 shows the experimental setup of DTP-BT. The setup is very similar to that for the direct tension testing of steel bars. The protruding steel bars at both ends were gripped in a $250 \mathrm{kN}$ MTS machine. Pull-out force and modes of failure are the main foci of this study. The load and displacement measured by the MTS machine were recorded for each specimen. The DTP-BT was conducted at a loading rate of $0.1 \mathrm{~mm} / \mathrm{min}$ before bar yielding and 1 $\mathrm{mm} / \mathrm{min}$ after bar yielding. After the test, each failed specimen was carefully inspected to identify the failure mode.

\subsection{Results and discussion 3.3.1 Modes of failure}

In the bond test, surface splitting is the dominant failure mode observed for DTP-BT specimens with $52 \mathrm{~mm} \mathrm{(c/d}$ ratio 3.25) cover, as illustrated in Fig. 7(a). For surface splitting failure, a single major crack is normally observed to form between the bar surface and the surface of the HSFRCC specimen. Careful inspection reveals a larger crack opening on the concrete surface than that at the surface of the steel bar. When the cover thickness was reduced, the failure mode changed from surface splitting to concrete spalling. This is illustrated in Fig. 7(b) for the DTP-BT specimen with $30 \mathrm{~mm}$ cover on one side and 52 $\mathrm{mm}$ cover on the other side. In this case, a fine crack could still be observed between the steel bar and the surface (on the side of the $30 \mathrm{~mm}$ cover), but failure was due to the concrete spalling, indicated by transverse cracks on the member surface. Careful post-failure inspection indicated that the spalled piece of concrete is in the shape of a cone. As illustrated by the diagram below the photograph in Fig. 7(b), when the cone crack reaches the external surfaces of the specimen, concrete spalling occurs. Since the spalled concrete is detached from the rest of the specimen, the part of steel bar within the spalled concrete is not 'bonded' to the specimen any more. The effective embedded length of the bar, and hence the bond capacity, are significantly reduced. The concrete spalling failure mode is therefore undesirable. In order to maintain the bond capacity for concrete cover of $30 \mathrm{~mm}$ (c/d ratio 1.875), the use of hooked end bars (HB) instead of straight bars (SB) was investigated. Hopefully, with the hook carrying part of the applied force, the stresses along the straight portion are reduced so it is less likely for a cone crack to form. The results 

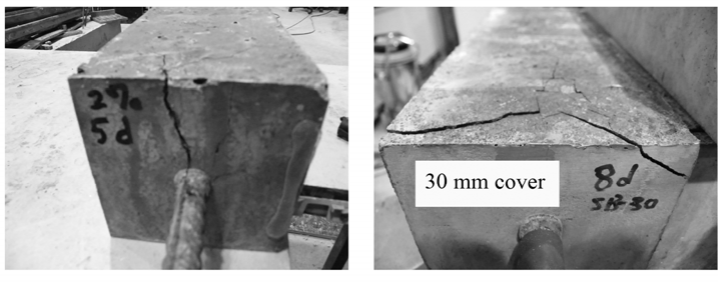

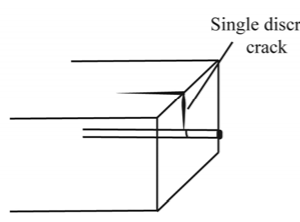

(a)

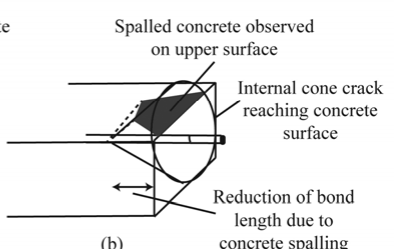
concrete spalling
Fig. 7 (a) Surface splitting failure (b) Concrete spalling failure.

will be discussed in a later section.

In this study, the bond capacity is represented by the pull-out strength, which is the ultimate stress carried by the tested steel bar during DTP-BT. The pull-out strength for different specimens is given in Table 3. As mentioned before, the reported value is the average obtained from three specimens.

\subsubsection{Effects of concrete strength and fiber content}

Here, we will compare the bond strength and mode of failure of specimens prepared with normal concrete $(70$ MPa, batches 1-2 in Table 4), high strength concrete (150 MPa, HSC) without fiber (batches 3-4) and HSFRCC specimens (batches 5-6). For the HSC specimens with no fiber (batches 3-4), the bond capacity is similar to that of normal concrete specimens containing steel stirrups (batches 1-2), for both $5 \mathrm{~d}$ and $8 \mathrm{~d}$ anchorage length. The results indicate the superior bond capacity of unconfined HSC, which is comparable to that of normal concrete with confinement provided by steel stirrups. However, for all the specimens in batches 1-4, the pull-out strength is well below the steel yield strength even at an anchorage length of $8 \mathrm{~d}$. Also, for all these specimens, failure occurred by surface splitting.

Comparing the test results of HSC specimens (batches $3-4$ ) and HSFRCC specimens with $2 \%$ fiber (batches 5-6), the average pull-out bar strength of HSFRCC specimens is about $150 \%$ higher for anchorage length of either $5 \mathrm{~d}$ or $8 \mathrm{~d}$. In both cases, surface splitting was observed. For the anchorage length of $8 \mathrm{~d}$, final failure occurred at $653 \mathrm{MPa}$. The enhanced bond capacity due to the crack bridging effect of fibers is clearly demonstrated by these results.

\subsubsection{Effects of steel bar type and cover}

We will first consider specimens with $52 \mathrm{~mm}$ cover (c/d ratio 3.25). Comparing the test results of different types of steel bar with both $5 \mathrm{~d}$ and $8 \mathrm{~d}$ anchorage lengths
Table 3 Experimental results of DTP-BT specimens.

\begin{tabular}{|c|c|c|c|}
\hline \multicolumn{2}{|c|}{ Batches } & $\begin{array}{c}\text { Average } \\
\text { pull-out } \\
\text { strength } \\
\text { (MPa) }\end{array}$ & Mode of failure \\
\hline 1 & C-5d-SB-0\% & 192 & surface splitting \\
\hline 2 & C-8d-SB-0\% & 230 & surface splitting \\
\hline 3 & HC-5d-SB-0\% & 191 & surface splitting \\
\hline 4 & HC-8d-SB-0\% & 257 & surface splitting \\
\hline 5 & HC-5d-SB-2\% & 466 & surface splitting \\
\hline 6 & HC-8d-SB-2\% & 653 & surface splitting \\
\hline 7 & HC-5d-HB-2\% & 320 & surface splitting \\
\hline 8 & HC-8d-HB-2\% & 597 & surface splitting \\
\hline 9 & HC-5d-NB-2\% & 455 & surface splitting \\
\hline 10 & HC-8d-NB-2\% & 662 & bar rupture \\
\hline 11 & HC-5d-SB30-2\% & 345 & concrete spalling \\
\hline 12 & HC-8d-SB30-2\% & 491 & concrete spalling \\
\hline 13 & HC-5d-HB30-2\% & 309 & surface splitting \\
\hline 14 & HC-8d-HB30-2\% & 600 & surface splitting \\
\hline
\end{tabular}

Table 4 HSFRCC joined precast slab specimens.

\begin{tabular}{|c|c|c|c|}
\hline Batches & $\begin{array}{c}\text { HSFRCC } \\
\text { joint }\end{array}$ & Bar type & $\begin{array}{c}\text { Concrete cover } \\
(\mathrm{mm})\end{array}$ \\
\hline Control & No & Continuous bar & \multirow{2}{*}{30} \\
\cline { 1 - 1 } HB-30 & \multirow{2}{*}{ Yes } & Hook bar & Straight bar \\
\cline { 1 - 1 } SB-50 & & 50 \\
\hline
\end{tabular}

(batches 5-10), the pull-out strength of straight bar (SB) specimens is similar to those with nuts (NB). With anchorage length of $5 \mathrm{~d}$, both $\mathrm{SB}$ and NB specimens achieved about $460 \mathrm{MPa}$, which is less than the yield strength of high yield steel. With anchorage length of $8 \mathrm{~d}$, pull-out strengths of both SB and NB specimens are over $650 \mathrm{MPa}$. Bar rupture was the mode of failure for all NB specimens. For the SB specimens, although the final failure mode was tensile surface splitting (matrix failure), the pull-out strength is close to that causing bar rupture. Compared with SB and NB specimens, the pull-out strength of hook bar (HB) specimens was lower. This is actually due to the interaction of the hook with the specimen boundary. As the arm length of the hook is about $50 \mathrm{~mm}$ and HSFRCC cover is only $52 \mathrm{~mm}$, the hook extends to a level just below the specimen surface. When the hooked bar is pulled, the bearing stress acting (along the arm of the hook) on the HSFRCC facilitates the opening of existing splitting cracks on the specimen surface. This leads to a reduction of the pull-out strength and increase in crack opening. In this case, the surface splitting crack that governed the failure was always found on the side of the hook. Also, for specimens with hooked end bars, the width of the surface splitting crack was always larger than those in specimens with other kinds of bars (SB and NB). The test results for the HB specimen is thus conservative for the real situation where the end of the hook is not close to the surface of a slab. 
For slabs inside a building, which are well-protected from the external environment, a $30 \mathrm{~mm}$ cover is more common. DTP-BT was therefore repeated for specimens of concrete cover $30 \mathrm{~mm}$ on one side. The cover on the other side of the bar was kept at $52 \mathrm{~mm}$. From previous test results, the performance of $\mathrm{SB}$ and $\mathrm{NB}$ specimens were very similar, so only SB and $\mathrm{HB}$ specimens were tested in this case. When the cover is reduced from 52 $\mathrm{mm}$ to $30 \mathrm{~mm}$ (c/d ratio from 3.25 to 1.875 ), the pull-out strength of SB specimens (batches 5-6 and 11-12) drops by about $25 \%$ (for both $5 \mathrm{~d}$ and $8 \mathrm{~d}$ anchorage length). Even with an anchorage length of $8 \mathrm{~d}$, steel yielding cannot be achieved. As mentioned in section 3.3.1, the propagation of a cone crack induces spalling failure. As a result, the bond capacity is significantly reduced and yielding cannot be reached. On the other hand, HB specimens with $52 \mathrm{~mm}$ cover or c/d ratio 3.25 (batches 8 and 9) showed similar pull-out strength as those with 30 $\mathrm{mm}$ or $\mathrm{c} / \mathrm{d}$ ratio 1.875 (batches 13 and 14). The failure mode of HB specimens with $30 \mathrm{~mm}$ cover on one side and anchorage length of $5 \mathrm{~d}$ and $8 \mathrm{~d}$ are shown in Figs. 8 and 9. Failure occurred by the formation of surface splitting cracks on the side with the hook (52 mm cover) as well as the other side (with $30 \mathrm{~mm}$ cover), but the failure should be governed by surface splitting at the side with $52 \mathrm{~mm}$ cover, as wider cracks can be observed on the specimen surface on the $52 \mathrm{~mm}$ side. As we mentioned above, the end of the hook is unlikely to be close to the member surface in real structural components, so the pull-out load measured in the test is a lower bound. In any case, the test results for $8 \mathrm{~d}$ anchorage length indicate that it is possible to increase the bond capacity with the hook when the concrete cover is small.

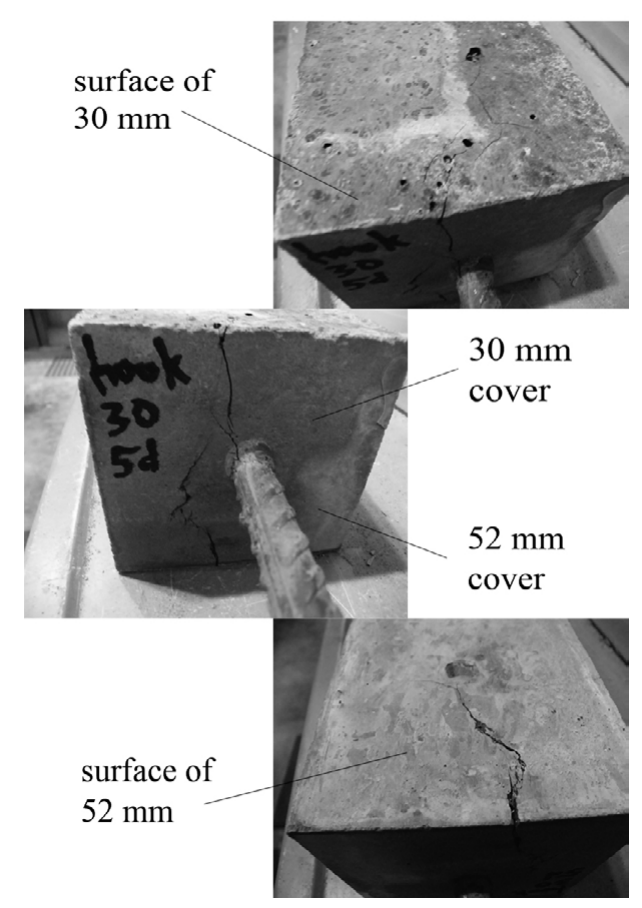

Fig. 8 Surface splitting for HC-5d-HB30-2\% specimens.

\section{Bending test of HSFRCC joined pre-cast slab}

\subsection{Specimens preparation}

To demonstrate the application of HSFRCC as joining material of precast concrete components, monolithic precast slabs as well as pre-cast slabs with HSFRCC joints were tested in bending. For each kind of specimen, two slabs were prepared. Figure 10 shows the diagrams of pre-cast slab with HSFRCC joint. Two precast concrete slab components with size $925 \times 350 \times 150(\mathrm{~mm})$ and lapping tensile reinforcements were joined by HSFRCC $(150 \times 350 \times 150(\mathrm{~mm}))$. In the slab component, $8 \mathrm{~mm}$ mild steel stirrups with $100 \mathrm{~mm}$ spacing were used to prevent shear failure. To fix the stirrups, two high yield steel bars with diameter $10 \mathrm{~mm}$ were placed on the top. Within the joint, either straight bars (SB) or hooked bars (HB) were placed. According to the test results of DTP-BT, a $50 \mathrm{~mm}$ concrete cover was employed for the case of SB while a $30 \mathrm{~mm}$ cover was used for the case of HB. Continuous concrete slabs with size $2000 \times 350 \times$ $150(\mathrm{~mm})$ and concrete cover $30 \mathrm{~mm}$ were prepared as control specimens. The various test parameters are shown in Table 4. As shown in Fig. 10(b), two tensile reinforcements of diameter $16 \mathrm{~mm}$ from each precast concrete slab component were lapped over a length of $8 \mathrm{~d}$ (128 mm). This should be sufficient to cause yielding of the reinforcement according to the test results of DTP-BT. The center-to-center spacing between the lapping tensile reinforcements is $80 \mathrm{~mm}$. To enhance the interfacial bond between the precast concrete slabs and HSFRCC joint, the slab component was prepared with two keys on the side to be joined (Fig. 10d).

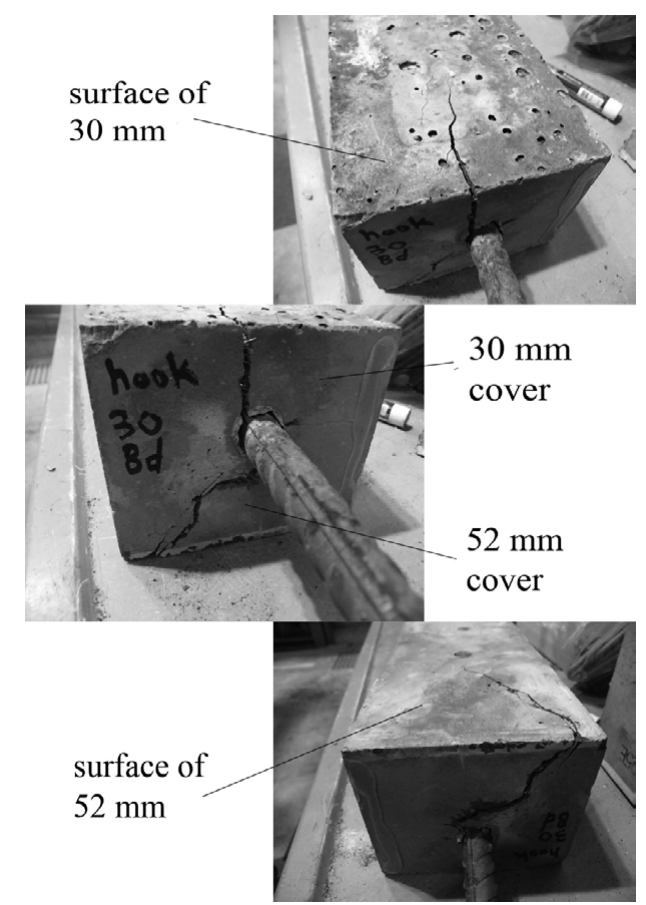

Fig. 9 Surface splitting for HC-8d-HB30-2\% specimens. 


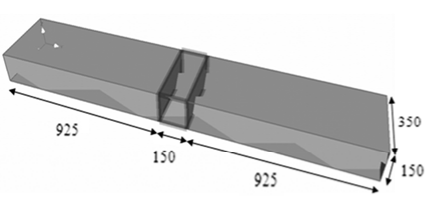

(a)

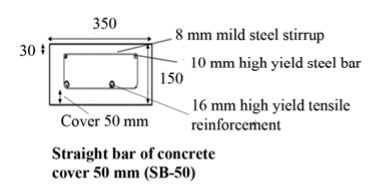

(c)

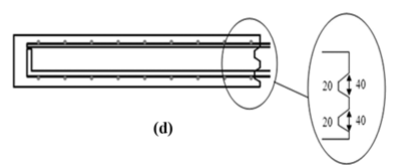

Fig. 10 Diagrams of HSFRCC joined pre-cast slab.

\subsection{Experimental setup}

Four-point bending test was performed for HSFRCC joined precast slabs in a DARTEC testing machine. The loading and support spans were $400 \mathrm{~mm}$ and $1800 \mathrm{~mm}$. The loading rate of $0.6 \mathrm{~mm} / \mathrm{min}$ was used and the test was terminated when the yielding portion of the slab was reached. The displacement at mid-span was measured by LVDTs. Cracks of the specimens were marked and highlighted during the test to show the crack pattern.

\subsection{Results and discussion}

\subsubsection{Load deflection curves}

The load deflection curves for various specimens are shown in Fig. 11. While two specimens have been tested for each kind of slab, only one curve is shown because there is little difference between the two results. For each kind of specimen, yielding of tensile reinforcements can be clearly observed in Fig. 11. The horizontal lines indicate the calculated failure loads of corresponding slabs with concrete cover $30 \mathrm{~mm}$ and $50 \mathrm{~mm}$ according to BS8110. The experimental results demonstrated that the bond capacity between HSFRCC and tensile reinforcements is sufficient to achieve yielding of the reinforcement. The load deflection curve of joined slab with 30 $\mathrm{mm}$ cover, containing hooked bars within the joint (HB-30), is very similar to that of the control monolithic specimen. In other words, the joining method is successful as the presence of the joint has no effect on the load capacity or ductility of the slab.

\subsubsection{Mode of failure}

Crack patterns of precast slab with HSFRCC joint as well as control monolithic slab are shown in Fig. 12. As similar crack patterns were observed for all joined slab specimens, only one HB-30 specimen and one concrete control specimen are shown in the figure. In both kinds of specimens, cracks were spread throughout the beam.
Within the maximum moment region (the middle 400 $\mathrm{mm}$ ), there were six cracks formed for the control specimen. For specimens with HSFRCC joint, two main cracks were found on the two sides of the joint. No flexural crack was observed within the joint, owing to the high strength of HSFRCC as well as its high resistance to crack opening. This observation indicates that the joint is stronger than other parts of the slab and so will not weaken the member. Figure 13 shows the main crack of the HB-30 specimen after the test. The crack propagated through the concrete key but the crack opening remained small beyond yielding of tensile reinforcement. No slipping of reinforcement was observed. The experimental results demonstrated the excellent performance of HSFRCC joints in maintaining structural behaviour of precast concrete slabs similar to that of continuous slabs.

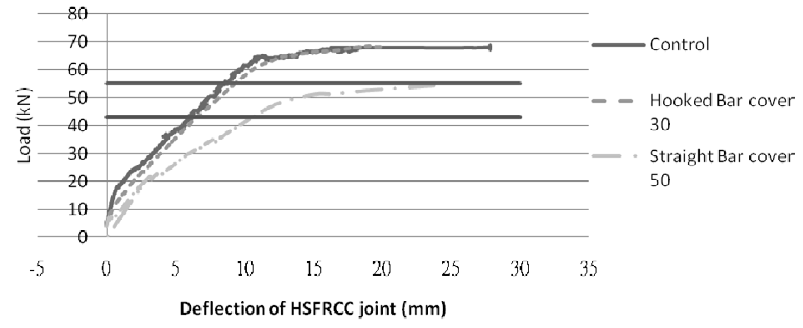

Fig. 11 Load displacement curves of HSFRCC joined precast slabs.

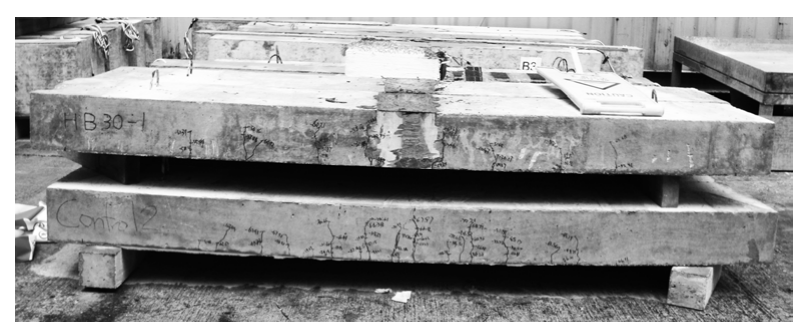

Fig. 12 Crack patterns of HB-30 and control specimens.

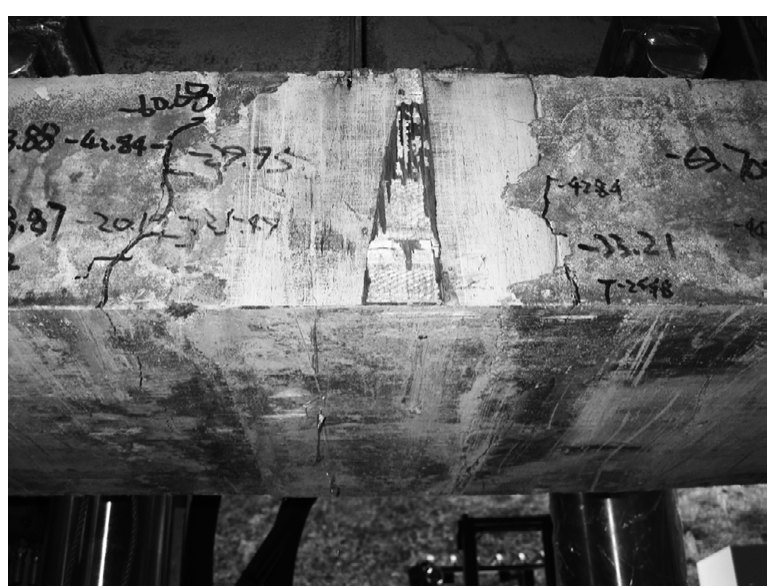

Fig. 13 Main crack of HB-30 specimen. 


\section{Conclusions}

This study focuses on the pull-out bond behaviour of steel bars in fiber reinforced high strength cementitious composites (HSFRCC) as well as bending behavior of HSFRCC joined precast slab. The following major findings can be highlighted.

For pull-out bond behaviour of steel bars in HSFRCC:

(1) Relative to plain HSC, the addition of $2 \%$ steel fiber increases the pull-out bond capacity by $150 \%$ for anchorage lengths $5 \mathrm{~d}$ and $8 \mathrm{~d}$ (where $\mathrm{d}$ is the steel bar diameter);

(2) Steel yielding can be ensured for a straight steel bar with anchorage length of $8 \mathrm{~d}$ and cover of $52 \mathrm{~mm}$ in DTP-BT. The construction of a short joint without transverse reinforcement is hence possible with the use of HSFRCC with only 2 volume percent of micro-steel fiber;

(3) When straight bars are used, the reduction of cover reduces the pull-out load. With the use of hooked end bars, the bearing stresses along the hook may compensate for the reduced bond capacity of a thinner concrete cover. Specifically, when the cover is reduced from 52 $\mathrm{mm}$ to $30 \mathrm{~mm}$, steel yielding can still be achieved for a hooked end bar with $8 \mathrm{~d}$ anchorage length.

For bending behavior of precast slab with HSFRCC joint:

(1) With a steel lap length of $8 \mathrm{~d}$ within the joint, the bond between tensile reinforcements and HSFRCC is sufficient for steel yielding to occur.

(2) For slabs with concrete cover of $30 \mathrm{~mm}$, the joined member (with hooked bar within the joint) has similar bending behavior to that in monolithic concrete slabs.

(3) No cracks are observed for the HSFRCC joint within the maximum moment region, confirming that the joint is stronger than the other parts.

The findings from this work demonstrate the feasibility of using HSFRCC in the construction of joints for pre-cast concrete members.

\section{Acknowledgements}

Financial support of the present work by the Hong Kong Research Grant Council, under CERG UST616306, is gratefully acknowledged.

\section{References}

Aarup, B., Karlsen, J. and Lindström, G., (2000). "Fiber reinforced high performance concrete for in-situ cast joints." Proceedings from International Symposium on High Performance Concrete, 25-27 September, 2000, Orlando, Florida, 379-387.

Azizinamini, A., Chisala, M. and Ghosh, S. K., (1995).

"Tension development length of reinforcing bars embedded in high-strength concrete." Engineering Structures, 17(7), 512-522.

Azizinamini, A., Stark, M., Roller, J. J. and Ghosh, S. K., (1993). "Bond performance of reinforcing bars embedded in high-strength concrete." ACI Structural Journal, 95(5), 554-561.

BS 8110-1, (1997). "British Standard Structural use of concrete." BSI.

Caliskan, S., (2003). "Aggregate/mortar interface: influence of silica fume at the micro- and macro-level." Cement and Concrete Composites, 25, 557-564.

Chan, Y. W. and Chu, S. H., (2004). "Effect of silica fume on steel fiber bond characteristics in reactive powder concrete." Cement and Concrete Research, 34(7), 1167-1172.

Fuller, W. B. and Thompson, J. E., (1926). "The Laws of Proportioning Concrete." A.S.C.E. Transactions, LIX, 67-172.

Hamad, B. S., Harajli, M. H. and Jumaa, G., (2001). "Effect of fiber reinforcement on bond strength of tension lap splices in high-strength concrete." $A C I$ Structural Journal, 98(5), 638-647.

Hamad, B. S. and Machaka, M. F., (1999). "Effect of transverse reinforcement on bond strength of reinforcing bars in silica fume concrete." Materials and Structures, 32(7), 468-476.

Hansen, L. P. and Heshe, G., (2001). "Static, fire and fatigue tests of ultra high-strength fibre reinforced concrete and ribbed bars." Nordic Concrete Research Publications.

Harajli, M. H., Hamad, B. S. and Karam, K., (2002). "Bond-slip response of reinforcing bars embedded in plain and fiber concrete." ASCE Journal of Materials, 14(6), 503-511.

Jensen, B. C., Jensen, L. R. and Hansen, L. P., (1995). "Connections in precast buildings using ultra high-strength fibre reinforced concrete." In: K. Aakjaer Ed. Proceedings Nordic Symposium on Modern Design of Concrete Structures, Aalborg University, Denmark, 63-74.

Ma, J. and Dietz, J., (2002). "Ultra high performance self compacting concrete." Lacer, No. 7, 33-42.

Shioya, T., Kurita, M., Bessho, T. and Tsuji, H., (1997). "Pre-cast concrete joint using steel fiber reinforced high strength mortar and/or H-beam." Proceedings of the Japanese Concrete Institute, 19(2), 1305-1310. (in Japanese)

Yang, Q. B. and Zhang, S. Q., (2004). "Self-desiccation mechanism of high performance concrete." Journal of Zhejiang University - Science A, 5(7), 1517-1523. 